\title{
Reseña de: Álvarez Medina, Silvina. La autonomía de las personas. Una capacidad relacional. Madrid: Centro de Estudios Jurídicos y Constitucionales, 2018.
}

\author{
Emanuela CARDoso ONOFRE DE AlENCAR \\ Doctoranda en la Facultad de Derecho \\ de la Universidad Autónoma de Madrid. \\ Docente y miembro del Instituto Universitario \\ de Estudios de la Mujer - IUEM-UAM.
}

Silvina Álvarez Medina nos acerca, en la obra La autonomía de las personas. Una capacidad relacional, a un reciente y estimulante desarrollo teórico sobre el concepto de autonomía personal. La autonomía ha sido un blanco tradicional de críticas, especialmente de teóricas feministas, por presuponer una concepción de la persona atomista, auto-suficiente y ubicada en un vacuo social. La idea de «autonomía relacional» es el esfuerzo de superar esas críticas y de analizar el concepto de autonomía y las condiciones de su ejercicio desde una perspectiva que toma en consideración la complejidad del contexto de las personas y las relaciones que se forman entre ellas, y que influyen en sus decisiones. Eso no quiere decir que se considere a las personas como ancladas en su entorno, en una especie de determinismo sociocultural o de esencialismo. Como advierte la autora, «ser relacionales» es un aspecto de la psicología de las personas del que no se puede prescindir y que se debe tener en cuenta a la hora de elaborar conceptos que quieren analizar el comportamiento humano (49).

El libro está dividido en dos partes. En la primera, «El concepto», la autora analiza el concepto de autonomía e identifica y discute sus elementos

Los contenidos de la revista se publican bajo una licencia de Creative Commons Reconocimiento 4.0 Internacional (CC BY 4.0)

Feminismo/s 33, junio 2019, pp. 347-349 
constitutivos. En la segunda parte, «El contexto», discute el ejercicio de esa capacidad en diferentes contextos que le permiten «apreciar y desentrañar esos extremos específicos que construyen el contexto relacional de cada individuo.» (71). La autora estudia la autonomía en contextos de pluralidad de valores, en que ocurren conflictos de derechos fundamentales; en el ámbito de la salud reproductiva, en que ciertas asimetrías relevantes entre varones y mujeres influyen en éstas a la hora de decidir sobre la maternidad; en el contexto de las relaciones médicas, también marcadas por importantes asimetrías de poder y de conocimientos, en que la autonomía cumple un papel fundamental a la hora de expresar un consentimiento informado; y, por fin, en el espacio público democrático, en que los mensajes de odio pueden influir en la percepción de las opciones disponibles a ciertos colectivos de personas. Esa elección metodológica es un acierto. Además de proporcionar una reflexión teórica sobre la complejidad del concepto de autonomía personal, permite al lector acercarse al análisis de su ejercicio y las dificultades de éste, en diferentes contextos de relaciones humanas.

Álvarez Medina escribe también un epílogo, titulado «El lugar de las emociones». Allí avanza una reflexión inicial y tentativa sobre el papel de las emociones en la toma de decisiones y en el ejercicio de la autonomía. Según la autora, «[1]a tarea de integrar las emociones en el análisis de la autonomía resulta impostergable si entendemos que el sujeto razona en sintonía con sus emociones, de las que no solo no puede desprenderse completamente -aunque sí puede esforzarse por atemperarlas o quitarles protagonismo-, sino que forman parte necesaria de la agencia moral» (175).

El libro, en su totalidad, es una aportación fundamental a la literatura sobre la autonomía personal en español. Sin embargo, en mi opinión, la parte más interesante es la que analiza el concepto de autonomía en clave relacional. Al incluir el contexto de las relaciones como una condición de posibilidad de la autonomía, la autora profundiza el desarrollo de su concepción de ese valor, lo que le permite describir mejor su ámbito de aplicación y precisar el alcance de su normatividad.

Álvarez Medina entiende el concepto de autonomía como una capacidad gradual que tiene tanto un aspecto racional, subjetivo e interno al sujeto, como también un aspecto relacional, que le es externo, pero que, sin embargo, influye en él a la hora de tomar decisiones. «El individuo que emprende la

Feminismo/s 33, junio 2019, pp. 347-349 
tarea de identificar preferencias, escoger y poner en marcha su voluntad, emprende una tarea compleja que involucra no solo su capacidad racional sino también su capacidad relacional en referencia a sus diversos vínculos con las personas y circunstancias del contexto en el que actúa o quiere actuar» (15).

La autora defiende que la autonomía personal está constituida no solo por la racionalidad y la independencia, elementos clásicos de ese concepto, sino también por las opciones relevantes. Este último elemento, inspirado en la posición de Joseph Raz, pero evitando su perfeccionismo, es, según Álvarez Medina, fundamental para una descripción adecuada de la autonomía. Las opciones tienen dos aspectos importantes que ofrecen una mirada más amplia hacia la autonomía personal. Por el aspecto objetivo, se observa que la autonomía no implica solo las habilidades cognitivas y volitivas de un sujeto racional, sino que el propio desarrollo de dichas habilidades se encuentra bajo la influencia de elementos externos, como son el contexto y las relaciones que conforman la vida de una persona. Por el aspecto subjetivo, se pone de relieve la interrelación que hay entre los aspectos cognitivos y psicológicos, y entre éstos y el contexto de oportunidades y relaciones. Esa interpretación amplia le permite desarrollar la idea de «opciones relacionales» (43) y la incorpora a su concepción de la autonomía personal como uno de sus elementos constitutivos.

Reconocer que el contexto de relaciones cumple un papel no solo en el desarrollo de las habilidades que configuran la autonomía, sino también que influyen en su ejercicio, permite poner el foco en la asimetría de poder, de oportunidades y de reconocimiento que caracteriza relaciones sociales de desigualdad. Ese es el caso, por ejemplo, de las relaciones de género, en que, como la autora analiza acertadamente, la socialización, el entorno del patriarcado y los estereotipos de género merman no solo las opciones disponibles para las mujeres, sino también la percepción de que ciertos cursos de acción son viables y legítimos para ellas.

La autonomía de la personas. Una capacidad relacional es una obra imprescindible para quienes tienen interés en el estudio de la autonomía personal y desean conocer cómo el contexto de relaciones, especialmente aquellas marcadamente desiguales, influye en la toma de decisiones. 